\title{
DISTRIBUSI KONDUKTIVITAS HIDRAULIK DARI HASIL UJI AKUIFER - CONSTANT HEAD PERMEABILITAS PADA BATUAN SEDIMEN SECARA HETEROGEN
}

\author{
Tedy Agung Cahyadi ${ }^{1)}$, \\ Sudarto Notosiswoyo ${ }^{2)}$, \\ Lilik Eko Widodo ${ }^{3}$, \\ Irwan Iskandar 4), \\ Suyono ${ }^{5)}$
}

1) Mahasiswa Pascasarjana, Rekayasa Pertambangan, ITB

2) 3) 4) Staff Pengajar Rekayasa Pertambangan, ITB

5) Staff Pengajar Teknik Pertambangan, UPN "Veteran" Yogyakarta

\begin{abstract}
ABSTRAK
Hydraulic conductivity is the ability of a rock to drain ground water at a certain speed. Hydraulic conductivity in fractured rock has a complexity (the degree of heterogeneity and anisotropic) higher than the hydraulic conductivity in sedimentary rocks. Generally in modeling the distribution hidroulik distribution, sedimentary rocks studied in homogeneous and isotropic. With hidroulik conductivity distribution in heterogeneous sedimentary rocks, will provide an understanding that in the natural distribution of nonuniform distribution of sedimentary rocks, although in one layer. Hidroulik conductivity values obtained from the test aquifer with constant head permeability method on samples of core drilling. Simulator SGeMS using kriging interpolation method is able to explain the distribution of conductivity distribution hidroulik in sedimentary rocks. Validation of the model by using the correlation coefficient between the model results and field test data.
\end{abstract}

Keywords: Hydraulic conductivity, Constant Head Permeability Test, Kriging, Sedimentary rocks, Heterogeneous

Konduktivitas hidroulik merupakan kemampuan suatu batuan untuk mengalirkan airtanah pada kecepatan tertentu. Konduktivitas hidraulik pada batuan terkekarkan memiliki kompleksitas (derajat heterogenitas dan anisotrop) yang lebih tinggi dibandingkan dengan konduktivitas hidraulik pada batuan sedimen. Umumnya dalam pembuatan model distribusi sebaran hidroulik, batuan sedimen dikaji secara homogen dan isotrop. Dengan melakukan distribusi konduktivitas hidroulik batuan sedimen secara heterogen, akan memberikan pemahaman bahwa di alam distribusi sebaran batuan sedimen tidak seragam walaupun dalam satu lapisan. Nilai konduktivitas hidroulik didapatkan dari uji akuifer dengan metode constant head permeabilitas pada sampel hasil pemboran inti. Simulator SGeMS menggunakan metode interpolasi kriging mampu menjelaskan sebaran distribusi konduktivitas hidroulik pada batuan sedimen. Validasi model dilakukan dengan menggunakan koefisien korelasi antara hasil model dan data uji dilapangan.

Kata Kunci : Konduktivitas Hidroulik, Uji Constan Head Permeabilitas, Kriging, Batuan Sedimen, Heterogen 


\section{LATAR BELAKANG}

Komponen utama dalam pemodelan aliran air tanah adalah persebaran nilai konduktivitas hidraulik. Konduktivitas hidraulik merupakan kemampuan suatu batuan untuk mengalirkan airtanah pada kecepatan tertentu. Konduktivitas hidraulik pada batuan terkekarkan memiliki kompleksitas (derajat heterogenitas dan anisotrop) yang lebih tinggi dibandingkan dengan konduktivitas hidraulik pada batuan sedimen. Umumnya dalam pembuatan model aliran air tanah, untuk menyederhanakan kondisi lapangan yang cukup komplek, parameter nilai konduktivitas hidraulik diasumsikan memiliki nilai yang sama dalam satu lapisan. Keadaan di lapangan, nilai konduktivitas hidroulik memiliki nilai yang berbeda - beda walaupun dalam satu lapisan batuan (heterogen). Hal itu bisa dibuktikan dari hasil pengujian akuifer dengan metode constant head permeabilitas. Penelitian ini merupakan data dari pengeboran inti sebanyak 7 lubang bor (Iskandar, 2007). Dari 7 lubang bor tersebut, dilakukan pengujian akuifer dengan metode constant head sebanyak 34 sampel. Kondisi litologi lokasi penelitian terdiri dari batuan sedimen (mudstone dan limestone), volcanic rock (andesite) dan quarter alluvial deposit. Data permeabilitas yang jumlahnya sangat terbatas dapat digunakan untuk menduga nilai konduktivitas hidraulik dengan cara interpolasi dengan metode kriging menggunakan open source SGeMS (Standford Geostatistic Modeling Software (Remy $N$ et al, 2006)). Metode tersebut telah terbukti untuk melakukan prediksi sebaran As berdasarkan pengaruh bobot, jarak, dan arah (Iskandar et al, 2007). Sebaran konduktivitas hidraulik yang beragam dikontrol dengan validasi model dan kondisi geologi. Hasil pemodelan konduktivitas hidraulik yang heterogen pada batuan sedimen tersebut dapat digunakan sebagai data masukan dalam input data permodelan aliran air tanah.

\section{TUJUAN PENELITIAN}

Penelitian ini bertujuan untuk menduga nilai konduktivitas hidraulik berdasarkan data uji constant head permeabilitas yang terbatas.

\section{METODOLOGI PENELITIAN}

Penelitian ini dilakukan dengan metode penggabungan antara teori, data lapangan dan hasil pengujian di laboratorium, sehingga dari ketiganya dapat diperoleh kesimpulan. Adapun tahapan metode yang dilaksanakan meliputi studi litaratur, hasil pengujian dari laboratorium, mengolah dan menganalisis hasil pengolahan data, serta mengambil kesimpulan.

\section{STUDI KASUS}

Lokasi penelitian berlokasi di daerah Sulawesi Utara. Litologi batuan yang ada di lokasi berupa batuan sedimen (mudstone dan limestone), batuan volcanic (andesite) dan quarter alluvial deposit. Sistem akuifer yang ada terdiri dari 2 jenis, akuifer dangkal yang terdiri dari deposit alluvial, lapisan lempung dan akuifer dalam yang terdiri dari batuan terkekarkan (mudstone, limestone dan andesite). 


\section{PELAKSANAAN PENELITIAN}

\subsection{Uji Akuifer - Constant Head Permeabilitas}

Uji ini dimaksudkan untuk mengetahui kemampuan batuan (kelulusan) material tanah atau batuan dalam meluluskan air dengan prinsip tekanan tetap. Sketsa alat pengujian constant head permeabilitas sebagai berikut :

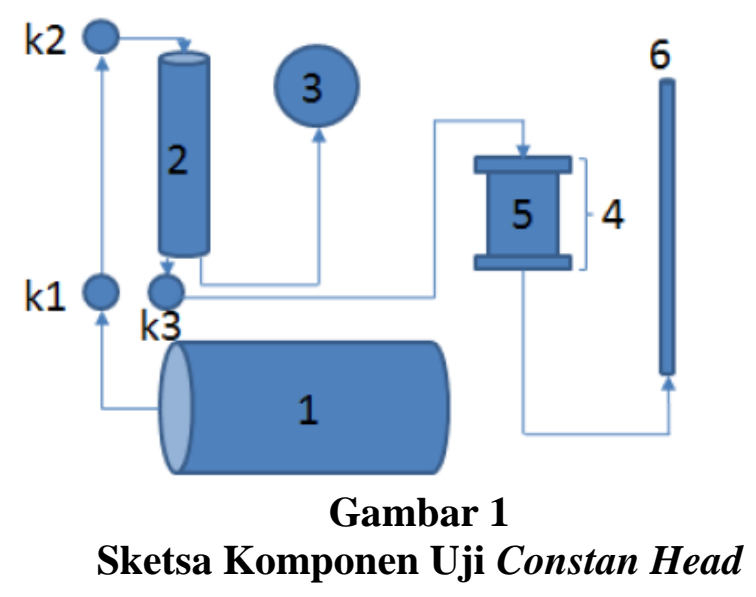

Keterangan :

1. Kompresor Udara

2. Tabung Air

3. Manometer Tekanan

4. Fitting

5. Tabung Sampel

6. Tabung Ukur Volume

7. Keran

Dengan menggunakan persamaan Darcy, pengujian constant head permeabilitas menghasilkan nilai konduktivitas hidraulik.

$\mathrm{K}=\frac{Q x L}{H x A}$

K merupakan nilai konduktivitas hidraulik (cm/dtk), Q merupakan debit aliran ( $\left.\mathrm{m}^{3} / \mathrm{dtk}\right), \mathrm{H}$ merupakan head $(\mathrm{cm})$, A merupakan luas penampang sampel $\left(\mathrm{cm}^{2}\right)$, L merupakan panjang sampel $(\mathrm{cm})$.

Hasil yang diperoleh dari pengujian akuifer sebagai berikut :

Tabel 1

Hasil Pengujian Constan Head Permeabilitas

\begin{tabular}{|c|c|c|c|c|c|c|}
\hline NO & BOR & $x$ & $\mathbf{Y}$ & $\mathbf{Z}$ & Permeability ( $\mathrm{m} / \mathrm{dtk})$ & $\log K$ \\
\hline 1 & \multirow{6}{*}{ BOR 1} & 24300 & -1200 & $-6,45$ & $1.14 \mathrm{E}-05$ & -4.94310 \\
\hline 2 & & 24300 & -1200 & $-12,50$ & $5.08 \mathrm{E}-06$ & -5.29414 \\
\hline 3 & & 24300 & -1200 & $-20,60$ & 0.000277 & -3.55752 \\
\hline 4 & & 24300 & -1200 & $-28,05$ & $1.81 \mathrm{E}-05$ & -4.74232 \\
\hline 5 & & 24300 & -1200 & $-33,15$ & 0.000547 & -3.26201 \\
\hline 6 & & 24300 & -1200 & $-35,55$ & $1.82 \mathrm{E}-05$ & -4.73993 \\
\hline 7 & \multirow{2}{*}{ BOR 2} & 22500 & -2300 & $-6,50$ & 0.00011 & -3.95787 \\
\hline 8 & & 22500 & -2300 & $-16,70$ & $2.55 \mathrm{E}-05$ & -4.59394 \\
\hline
\end{tabular}




\begin{tabular}{|c|c|c|c|c|c|c|}
\hline NO & BOR & $\mathbf{x}$ & $\mathbf{Y}$ & $\mathbf{Z}$ & Permeability (m/dtk) & $\log \mathrm{K}$ \\
\hline 9 & & 22500 & -2300 & $-21,50$ & $3.88 \mathrm{E}-05$ & -4.41128 \\
\hline 10 & & 22500 & -2300 & $-26,00$ & $6.74 \mathrm{E}-05$ & -4.17114 \\
\hline 11 & & 22500 & -2300 & $-30,50$ & $2.35 \mathrm{E}-05$ & -4.62841 \\
\hline 12 & & 22500 & -2300 & $-35,90$ & 0.000104 & -3.98186 \\
\hline 13 & & 22500 & -2300 & $-39,50$ & $5.65 \mathrm{E}-06$ & -5.24765 \\
\hline 14 & \multirow{4}{*}{ BOR 3} & 23200 & -2000 & $-3,50$ & $3.44 \mathrm{E}-05$ & -4.46404 \\
\hline 15 & & 23200 & -2000 & $-12,50$ & 0.000713 & -3.14702 \\
\hline 16 & & 23200 & -2000 & $-32,90$ & 0.000127 & -3.89582 \\
\hline 17 & & 23200 & -2000 & $-40,30$ & 0.000269 & -3.57007 \\
\hline 18 & \multirow{3}{*}{ BOR 4} & 22700 & -1300 & $-6,20$ & 3.89E-05 & -4.40954 \\
\hline 19 & & 22700 & -1300 & $-13,40$ & 2.67E-06 & -5.57303 \\
\hline 20 & & 22700 & -1300 & $-14,00$ & 9.98E-05 & -4.00065 \\
\hline 21 & \multirow{3}{*}{ BOR 5} & 23000 & 1000 & $-3,30$ & $1.5 \mathrm{E}-05$ & -4.82257 \\
\hline 22 & & 23000 & 1000 & $-6,00$ & $1.85 \mathrm{E}-05$ & -4.73239 \\
\hline 23 & & 23000 & 1000 & $-7,70$ & 8.22E-05 & -4.08526 \\
\hline 24 & \multirow{5}{*}{ BOR 6} & 23800 & 0 & $-12,40$ & 2.89E-05 & -4.53857 \\
\hline 25 & & 23800 & 0 & $-18,10$ & 0.000339 & -3.46965 \\
\hline 26 & & 23800 & 0 & $-24,40$ & $7.29 \mathrm{E}-05$ & -4.13717 \\
\hline 27 & & 23800 & 0 & $-36,40$ & 0.000125 & -3.90309 \\
\hline 28 & & 23800 & 0 & $-39,40$ & 0.000478 & -3.32056 \\
\hline 29 & \multirow{6}{*}{ BOR 7} & 25000 & -1100 & $-6,00$ & $2.08 \mathrm{E}-05$ & -4.68124 \\
\hline 30 & & 25000 & -1100 & $-11,10$ & $3.24 \mathrm{E}-05$ & -4.48936 \\
\hline 31 & & 25000 & -1100 & $-21,25$ & 7.41E-05 & -4.13033 \\
\hline 32 & & 25000 & -1100 & $-23,20$ & $1.85 \mathrm{E}-05$ & -4.73239 \\
\hline 33 & & 25000 & -1100 & $-29,10$ & $1.5 \mathrm{E}-06$ & -5.82257 \\
\hline 34 & & 25000 & -1100 & $-47,10$ & $2.08 \mathrm{E}-05$ & -4.68124 \\
\hline
\end{tabular}

\subsection{Pemodelan Sebaran Konduktivitas Hidraulik dengan Kriging}

Model kriging mengestimasi nilai pada daerah tidak tersampel dengan melakukan perataan bobot sampel di sekitarnya berdasarkan jarak dan arah. Korelasi antar data yang berdekatan dimodelkan sebagai fungsi jarak geografis antar data pada area studi, didefinisikan sebagai variogram. Kriging sebagai teknik interpolasi telah diterapkan secara luas untuk memperkirakan variabel hidrogeologi di lokasi unsampled dari titik data pencar, seperti transmisivitas dan konduktivitas hidraulik (Fabbri, 1997) dan kontaminan (Iskandar, et al 2011). Variogram mencerminkan korelasi spasial pada sampel data di lapangan. Variogram didefinisikan sebagai berikut :

$\gamma(\mathbf{h})=\frac{1}{2 n(\mathbf{h})} \sum_{i=1}^{n(\mathbf{h})}\left(z_{1}\left(\mathbf{x}_{i}+\mathbf{h}\right)-z_{1}\left(\mathbf{x}_{i}\right)\right)^{2}$

$\mathbf{x}=$ koordinat/lokasi, $\mathbf{h}=$ jarak terpisah, $\mathrm{n}(\mathbf{h})=$ jumlah sampel pasangan terhadap $\mathrm{h}, \mathrm{z}=$ bobot data 
Jenis semivariogram yang digunakan tipe spherical. Setelah semivariogram dibentuk, kriging dapat mulai menaksir nilai parameter primer pada lokasi yang tidak tersampel dengan menggunakan bobot rataan.

$$
z_{0}^{*}\left(\mathbf{x}_{0}\right)=\sum_{i=1}^{n 1} \lambda_{1 i} z_{1}\left(\mathbf{x}_{i}\right)
$$

Dimana $\mathrm{n}$ adalah jumlah tetangga terdekat dari $\mathrm{z}_{1}$ dan $\mathrm{z}_{2}$. Nilai bobot untuk masing-masing data didapat dengan memecahkan persamaan linier dengan meminimalkan nilai variansi kriging.

Dari 34 data inti bor yang telah dilakukan uji constant head, sebanyak 5 sampel diambil untuk tidak digunakan dalam proses pemodelan. Fungsi sampel yang diambil tersebut digunakan proses validasi, yaitu membandingkan hasil sebaran konduktivitas hidraulik berdasarkan hasil model dan data kondisi sebenarnya dari lapangan.

Dengan menggunakan semivariogram spherical, variogram yang diperoleh berdasarkan sebaran sampel 29 buah sebagai berikut :

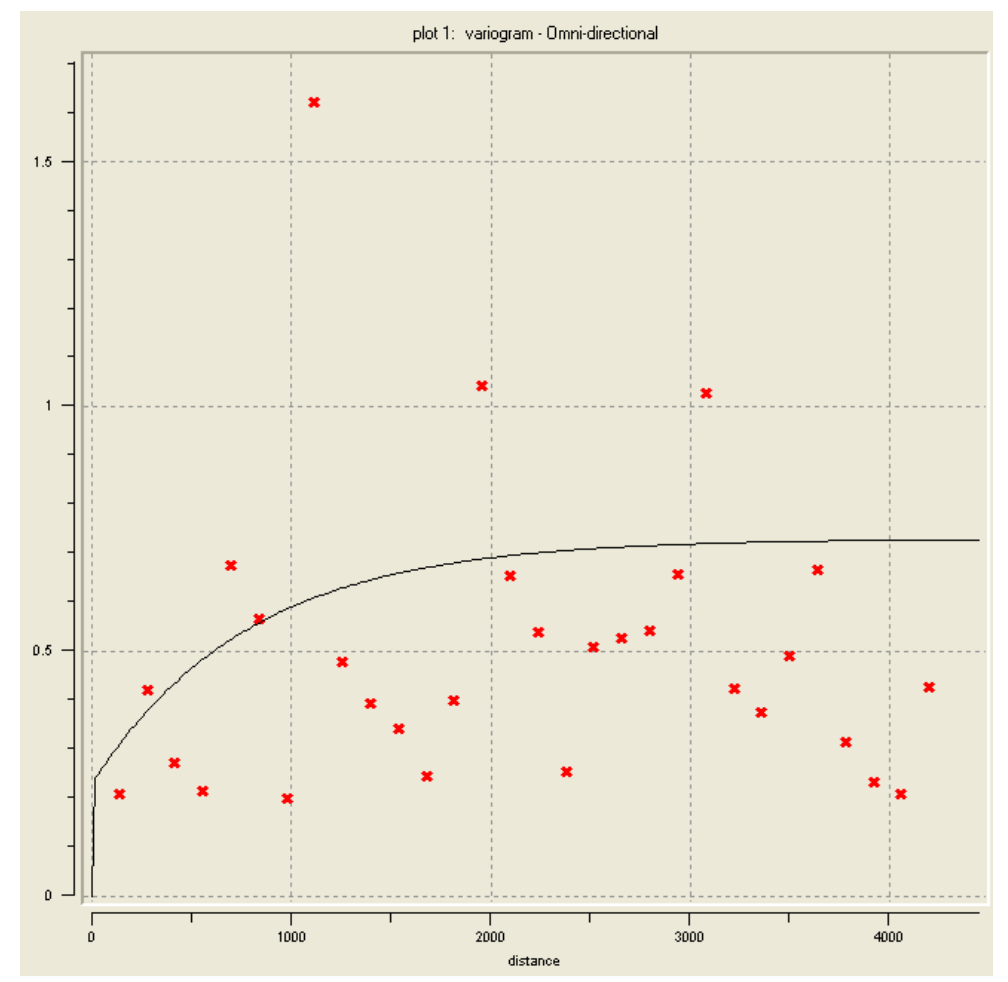

Gambar 2

Sebaran Semivariogram

Distribusi semivariogram dibuat mulai dari azimuth $0,45,90,135$. Berdasarkan hasil intepretasi data, didapatkan nilai semivariogram yang sama pada semua arah. Hal ini menunjukkan bahwa kondisi lapisan batuan relative datar pada semua arah. Nilai sill pada semivariogram omnidirectional tercapai pada nilai 0,5 , sedangkan nugget effect bernilai 0,27 . 
Pendugaan konduktivitas hidraulik dengan metode kriging dibuat dalam area dengan dimensi $2700 \mathrm{~m} \times 5500 \mathrm{~m} \times 4700 \mathrm{~m}$. Untuk melihat hasil pendugaan konduktivitas hidraulik dengan metode kriging ini secara lebih detail, hasil direpresentasikan dalam bentuk fence diagram atau slice dalam arah X, Y, Z. Hasil estimasi pada daerah penelitian dapat dilihat.

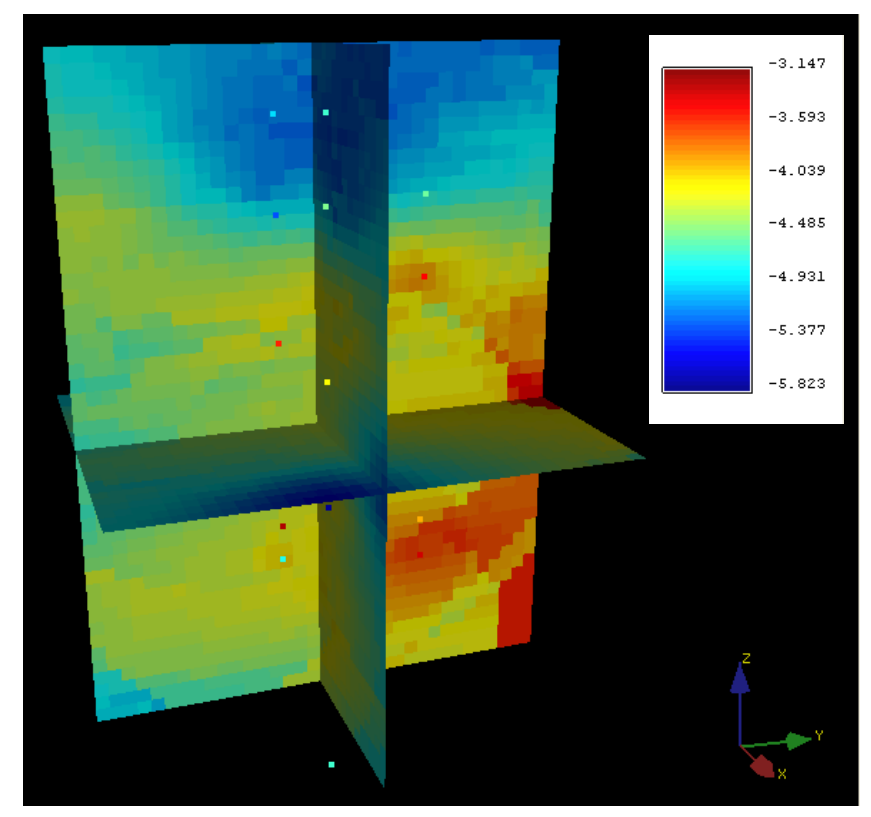

Gambar 3

3 D Sebaran Konduktivitas Hidraulik

\section{PEMBAHASAN}

\subsection{Hasil Uji Permeabilitas}

Hasil pengujian nilai konduktivitas hidraulik berdasarkan uji constant head, menunjukkan rentangan nilai dari $1,5 \times 10^{-6} \mathrm{~m} / \mathrm{dtk}-0,7 \times 10^{-3} \mathrm{~m} / \mathrm{dtk}$. Nilai tersebut merupakan representasi dari litologi berupa lapisan aluvial, batuan sedimen, serta batuan terkekarkan. Apabila sebaran nilai konduktivitas hidraulik tersebut diproyeksikan dalam bentuk histogram, akan menghasilkan sebaran data yang cenderung miring ke kiri (skewnes kiri). Hal ini digunakan untuk melihat sebaran data yang dihasilkan pada saat pemodelan konduktivitas hidraulik. Nilai sebaran konduktivitas hidraulik dikonversikan dalam bentuk $\log$ K. Nilai konduktivitas hidraulik $\log -5$, mempunyai arti nilai tersebut adalah $10^{-5}$ $\mathrm{m} / \mathrm{dtk}$.

\begin{tabular}{|c|c|}
\hline log $\boldsymbol{K}$ & Jumlah Sampel \\
\hline-5 & 4 \\
\hline-4.5 & 11 \\
\hline-4 & 9 \\
\hline-3.5 & 6 \\
\hline More & 4 \\
\hline
\end{tabular}

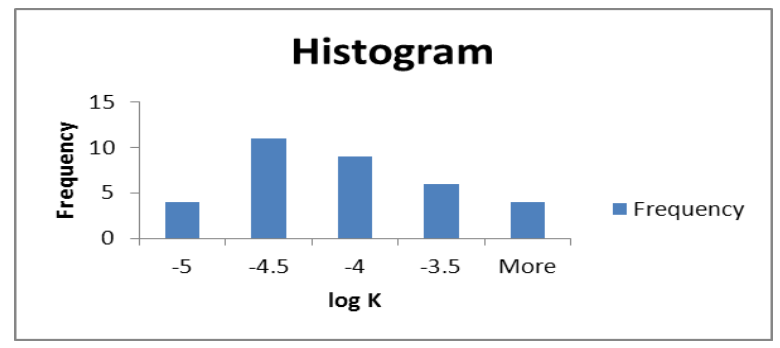

Gambar 4

Persebaran Data Awal sebelum Dilakukan Pemodelan 


\subsection{Hasil Pemodelan Distribusi Kondutivitas Hidraulik}

Berdasarkan hasil penentuan konduktivitas hidraulik dengan menggunakan metoda kriging, dari jumlah 29 buah data menghasilkan 44.415 nilai konduktivitas hidraulik, yang memiliki nilai yang berbeda antara titik blok model yang satu dengan yang lainnya. Untuk melihat sebaran data yang dihasilkan dari model tersebut perlu dibuat histogram. Sebaran data menghasilkan pola yang mirip dengan kondisi data awal, yaitu sebaran data yang cenderung terdistribusi miring ke kiri (skewnes kiri).

\begin{tabular}{|r|r|}
\hline \multicolumn{1}{|l|}{$\log \boldsymbol{K}$} & Jumlah Hasil Model \\
\hline-5 & 9751 \\
\hline-4.5 & 31339 \\
\hline-4 & 3210 \\
\hline-3.5 & 80 \\
\hline More & 35 \\
\hline
\end{tabular}

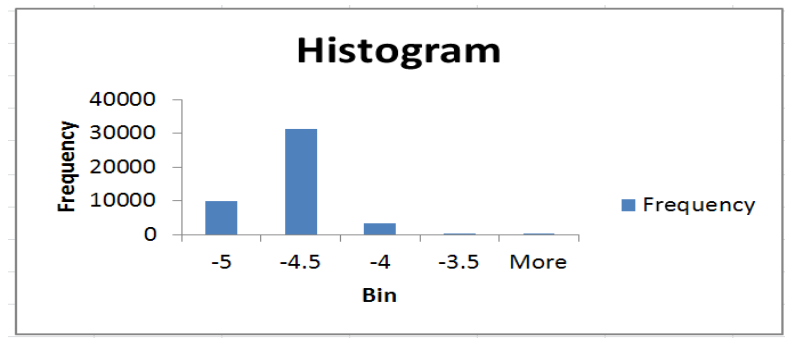

Gambar 5

Persebaran Data Awal setelah Dilakukan Pemodelan

Histogram tersebut memberikan gambaran, bahwa nilai permeabilitas batuan yang ada di alam dari titik yang yang satu ke titik yang lainnya memiliki nilai yang berbeda (heterogen). Sehingga dalam satu lapisan litologi, nilai konduktivitas hidraulik akan bervariasi.

Hasil variogram menunjukkan bahwa, dengan azimuth 0, 45, 90, dan 135 memberikan sebaran yang relative sama pada range $2.500 \mathrm{~m}$. Gambar dibawah ini menunjukkan perbedaan lapisan batuan ditunjukkan oleh perbedaan warna dominan biru dan kuning ke merah. Sehingga hal itu menunjukkan bahwa walau dalam satu lapisan litologi yang sama, memberikan distribusi sebaran nilai konduktivitas hidraulik yang relative heteregon.

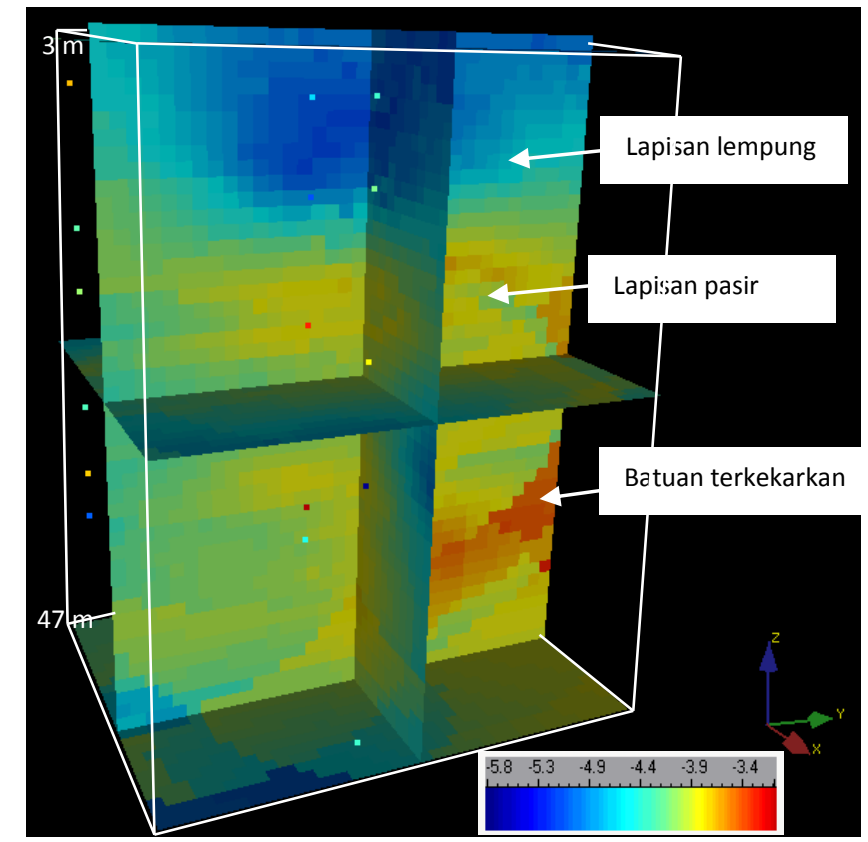

Gambar 6

Lapisan Batuan Sedimen dan Batuan Terkekarkan 
Nilai konduktivitas hidraulik pada warna biru merupakan representasi dari lapisan lempung yang relative impermeabel, sehingga mencerminkan nilai konduktivitas hidraulik yang kecil. Lapisan pasir pada model ditunjukkan pada warna kuning yang menunjukkan lapisan akuifer pada kondisi yang dangkal. Nilai permeabilitas yang besar dijumpai pada lokasi penelitian di arah utara. Warna merah tersebut merupakan representasi akuifer dalam yang berada pada batuan terkekarkan, yaitu batugamping.

Untuk mengukur ketepatan estimasi nilai konduktivitas hidraulik di daerah penelitian, metode yang digunakan adalah cross-validation. Lima (5) sampel yang tidak digunakan sebagai data masukan model berfungsi untuk membandingkan hasil distribusi sebaran konduktivitas hidraulik berdasarkan metoda kriging. Perbandingan hasil nilai K dari model dan data uji akuifer disajikan pada tabel berikut :

Tabel 2

Perbandingan Hasil Konduktivitas Hidraulik Model dan Uji Constan Head Permeabiltas

\begin{tabular}{|c|r|c|c|c|}
\hline $\mathbf{x}$ & \multicolumn{1}{|c|}{$\mathbf{y}$} & \multicolumn{1}{c|}{$\mathbf{z}$} & \multicolumn{1}{c|}{ log K obs } & Log K prediksi \\
\hline 24300 & -1200 & -2805 & -4.7423214 & -4.824351 \\
\hline 22500 & -2300 & -2600 & -4.1711395 & -3.916717 \\
\hline 23200 & -2000 & -3290 & -3.8958228 & -3.601869 \\
\hline 23800 & 0 & -2440 & -4.1371732 & -3.424596 \\
\hline 25000 & -1100 & -2320 & -4.7323938 & -4.813883 \\
\hline
\end{tabular}

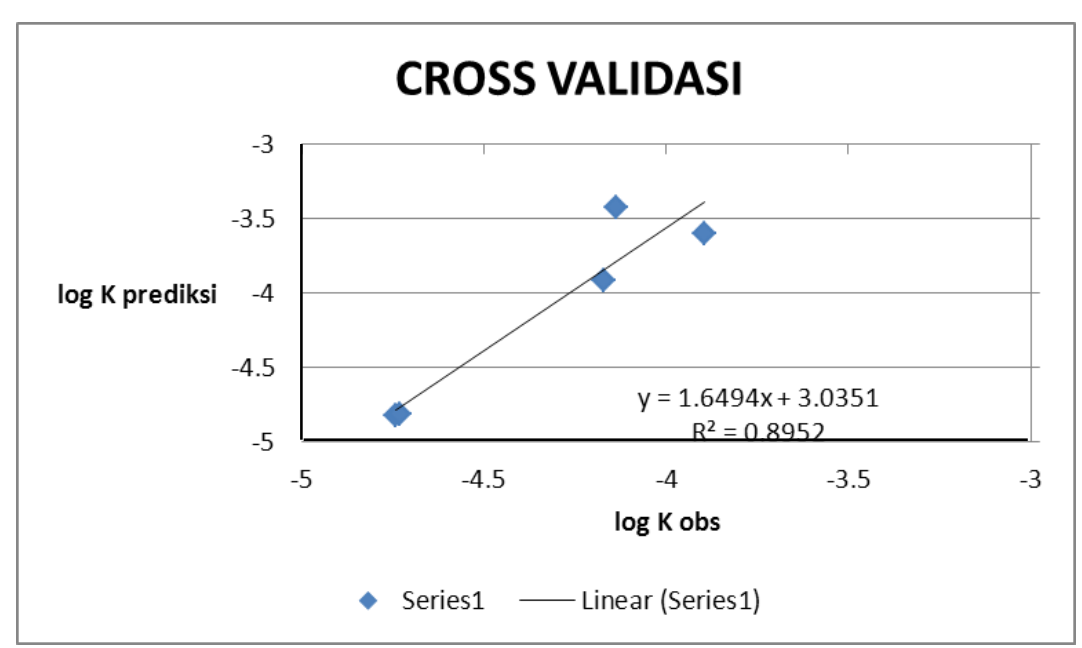

Gambar 7

\section{Hubungan Data Konduktivitas Hidraulik Model dan Uji Constan Head Permeabiltas}

Verifikasi model dilakukan dengan tujuan agar pemodelan yang dibuat sesuai dengan kondisi lapangan yang sebenarnya. Hasil pemodelan dari SeGMS dibandingkan hasil 5 sampel uji yang tidak digunakan dalam data masukan model. Sesuai atau tidaknya model matematis tersebut dengan data yang digunakan dapat ditunjukkan dengan mengetahui besarnya nilai $\mathrm{r}^{2}$ atau juga yang disebut sebagai koefisien determinasi (cooficient of determination). 
Koefisien determinasi dalam statistika dapat diintepretasikan sebagai proporsi dari variasi yang ada dalam nilai y dan dijelaskan oleh model persamaan regresi. Dengan kata lain, koefisien determinasi menunjukkan seberapa jauh kesalahan dalam memprakirakan besarnya y dapat direduksi dengan menggunakan informasi yang dimiliki variable $\mathrm{x}$.

Model persamaan dianggap sempurna apabila nilai $r^{2}=1$. Sebaliknya, apabila variasi yang ada pada nilai y tidak ada yang bisa dijelaskan oleh model persamaan regresi yang diajukan, maka nilai $\mathbf{r}^{2}=0$. Dengan demikian, model persamaan regresi dikatakan semakin baik apabila besarnya ${ }^{2}$ mendekati 1 (Ating, S. 2006).

Hasil $\mathrm{r}^{2}$ pada pemodelan tersebut menghasilkan nilai sebesar 0,89. Angka tersebut menunjukkan bahwa antara data hasil pemodelan dengan nilai konduktivitas hidraulik yang sebenarnya menghasilkan hubungan angka cukup signifikan. Sehingga dengan hasil distribusi sebaran nilai K dengan cara kriging mencerminkan bahwa batuan sedimen yang ada di alam memiliki nilai $\mathrm{K}$ yang heterogen.

\section{KESIMPULAN}

Distribusi sebaran konduktivitas hidraulik berdasarkan hasil uji akuifer constan head permeabilitas dengan metode kriging mampu menjelaskan keberadaan nilai $\mathrm{K}$ di batuan sedimen yang relative heterogen. Heterogenitas nilai $\mathrm{K}$ sangat mempengaruhi suatu aliran air pada media airtanah. Metode kriging terbukti mampu menduga nilai konduktivitas hidraulik pada daerah yang tidak memiliki data.

\section{DAFTAR PUSTAKA}

Remy N., Boucher A., Wu J. (2006) : SGeMS User Guide.

Iskandar I., Koike K, (2011) : Distinguishing potential sources of arsenic released to groundwater around a fault zone containing a minesite.

Fabbri, P., (1997) : Transmissivity in the geothermal Euganean basin: a geostatistical analysis. Ground Water 35 (5), $881-887$.

Ating, S., (2006) : Aplikasi Statistika dalam Penelitian, Pustaka Setia, Bandung.

\section{UCAPAN TERIMAKASIH}

Penulis mengucapkan terimakasih kepada segenap rekan - rekan Prodi Rekayasa Pertambangan dan Teknik Air Tanah - ITB. Selain itu juga penulis mengucapkan terimakasih kepada Laboratorium Hidrogeologi Tambang-ITB, Aris Arnanto, Odus Natan, Novita Douw, Indra Bagus, dkk yang telah memberikan bantuan sehingga makalah ini dapat dipresentasikan. 